\title{
SEMI-SOLID HEAT TREATMENT OF HYPEREUTECTIC Al-18\% Si ALLOY CONTAINING IRON-RICH INTERMETALLICS
}

\author{
M. Ramadan ${ }^{1}$, N. Fathy ${ }^{2}$, M. A. Waly ${ }^{3}$, A. A. Nofal ${ }^{4}$ \\ ${ }^{1}$ Senior Researcher, Foundry Technology Department, Central Metallurgical Research and Development Institute \\ (CMRDI), Cairo, Egypt \\ ${ }^{2}$ Assistant Professor, Physics Department, University of Hail, Saudi Arabia \\ ${ }^{3}$ Professor, Foundry Technology Department, Central Metallurgical Research and Development Institute (CMRDI), \\ Cairo, Egypt \\ ${ }^{4}$ Professor, Foundry Technology Department, Central Metallurgical Research and Development Institute (CMRDI), \\ Cairo, Egypt
}

\begin{abstract}
In this research the effect of semi-solid heat treatment on matrix structure and iron-rich intermetallics of hyper-eutectic Al-18\% Si containing $0.95 \% \mathrm{Fe}$ is studied. Semi-solid heat treatment at heating temperature of $585{ }^{\circ} \mathrm{C}$ shows a significant refinement of ironrich intermetallic phase. In as cast samples, needle-like iron-rich intermetallics phases was observed, otherwise, plate-like and fine plate-like iron-rich intermetallics phases was observed for all samples heat treated in semi-solid state. Hardness values for semi-solid heat treated Al-18\% Si Alloy for all heating time range (10-40 min) are relatively higher compared with the as cast one. Hardness value of $72.5 \mathrm{HRB}$ is achieved by heating Al-18\% Si alloy at heating temperature of $585{ }^{\circ} \mathrm{C}$ for $20 \mathrm{~min}$. At the early stages of heating time (up to $20 \mathrm{~min}$ ), a significant decreases of weight loss is observed in Al-18\% Si alloy when semi-solid isothermal heat treatment was applied at $585^{\circ} \mathrm{C}$ heating temperature. However, semi-solid isothermal heat treatment performed above heating time of $25 \mathrm{~min}$ might result in increases of weight. The optimum semi-solid heating treatment condition was achieved at the temperature of $565^{\circ} \mathrm{C}$ for the range of 15 to 25 mins.
\end{abstract}

Keywords: Al-18\% Si, Intermetallics, Heat treatment, Microstructure, Semi-solid.

\section{INTRODUCTION}

It is well established that hypereutectic Al-Si cast alloys have the good potential for tribological applications. Silicon as a hard material increases the wear resistance of $\mathrm{Al}-\mathrm{Si}$ hypereutectic alloys. The presence of Fe and its compounds can be a problem in hypereutectic $\mathrm{Al}-\mathrm{Si}$ alloys. Iron as an impurity in Al-Si alloys or as necessaryelement in the diecast process can leave some serious detrimental effects on the mechanical properties of the casting parts. This is due mainly to the precipitation of brittle $\beta-\mathrm{Al} 5 \mathrm{FeSi}$ intermetallics that appear as needles or plate-like morphologies in the microstructure. However,in $\mathrm{Al}-\mathrm{Si}$ piston alloys, iron is a desirable element that helps to enhance high temperature properties and thermal stability of the alloy. Attempts have to be made to modify the negative effects of iron intermetallics, e.g., by refining their size and by modifying them to the lessdeleterious morphologies [1].

Hypereutectic Al-Si alloys such as A390 (Al-17\% Si-4.5\% $\mathrm{Cu}-0.5 \% \mathrm{Mg}$ ) are used in applications that require high resistance to wear and corrosion, good mechanical properties, low thermal expansion and reduced density. These properties are of particular interest to the automobile industry for the production of fuel-efficient vehicles using light-weight components produced from these alloys such as connecting rods, pistons, air conditioner compressors, cylinder liners and engine blocks [2]. Their good mechanical properties and high resistance to wear are essentially attributed to the presence of hard primary silicon particles distributed in the matrix. Therefore, the size and morphology of primary silicon in hypereutectic Al-Si alloys influence the mechanical properties of the alloys [3].

Taghiabadi et al. [4] have shown that addition of about 0.7 wt.\% Fe increased the hardness and improved the wear resistance of the F332 Al-Si alloy. Addition of iron up to 2.5 wt.\% increased the hardness, but decreased the wear resistance.

This investigation has been focused on the effect semi-solid heat treatment on iron-rich intermetallics and to study their effects on hardness and wear loss of hypereutectic $\mathrm{Al}-\mathrm{Si}$ piston alloy containing $0.95 \% \mathrm{Fe}$.

\section{EXPERIMENTAL}

The alloy was melted in $30 \mathrm{~kg}$ capacity medium frequency induction furnace. The chemical composition of alloy samples is shown in Table 1. After flux treated, the melt was held at $750{ }^{\circ} \mathrm{C}$ for $5 \mathrm{~min}$ and then poured into a permanent mould whose size of mould cavity is $\varnothing 50$ $\mathrm{mm} \times 200 \mathrm{~mm}$.

The differential scanning calorimetric analysis (DSC) for the studied Al-Si alloy was conducted showing that solidus 
temperature of $575.5^{\circ} \mathrm{C}$, as shown in Fig.1. Specimens of approximate dimensions $15 \times 15 \times 15 \mathrm{~mm}$ were cut for isothermal heat treatment as well as microstructure examination and hardness measurements. All specimens were heated to $585{ }^{0} \mathrm{C}$ hold for $10,20,30$ and 40 mins, respectively in an electrically heated resistance furnace with heating rate of $10{ }^{\circ} \mathrm{C} \cdot \mathrm{min}^{-1}$. After the semi-solid heat treatment, the samples were taken out immediately for air cooling.

Table 1Chemical analysis of Al-Si samples, wt.-\%

\begin{tabular}{|l|l|l|l|}
\hline $\mathrm{Si}$ & 17.95 & $\mathrm{Mn}$ & 0.02 \\
\hline $\mathrm{Cu}$ & 4.20 & $\mathrm{Sn}$ & 0.07 \\
\hline $\mathrm{Mg}$ & 0.55 & $\mathrm{Ti}$ & 0.06 \\
\hline $\mathrm{Fe}$ & 0.95 & $\mathrm{~V}$ & 0.03 \\
\hline $\mathrm{S}$ & 0.01 & $\mathrm{~T}_{\mathrm{L}}\left({ }^{0} \mathrm{C}\right)^{\mathrm{a}}$ & 690 \\
\hline $\mathrm{Ni}$ & 0.33 & $\mathrm{~T}_{\mathrm{S}}\left({ }^{0} \mathrm{C}\right)^{\mathrm{b}}$ & 575.5 \\
\hline
\end{tabular}

${ }^{\mathrm{a}}$ Liquidus temperature, ${ }^{\mathrm{b}}$ Solidus temperature

Specimens in either as cast or heat treated condition were grinded, polished, etched with a solution consist of $0.5 \% \mathrm{HF}$ and $99.5 \% \mathrm{H}_{2} \mathrm{O}$ and examined metallographically using an optical microscope and photomicrographs were taken.

Microstructure and iron-rich intermetallics were measured and analyzed with Scentis image analyzer software (with errors 5\%). Rockwell hardness test were also performed using $1 / 16$ inch diameter ball and $100 \mathrm{~kg}_{\mathrm{f}}$ load. The wear tests were conducted on pin-on-disc machine. It consists of a hardened steel disc and a holder for specimen pin. The tests were conducted at content load of 0.4 bar and a sliding velocity on $150 \mathrm{rpm}$ for constant time of $30 \mathrm{~min}$.

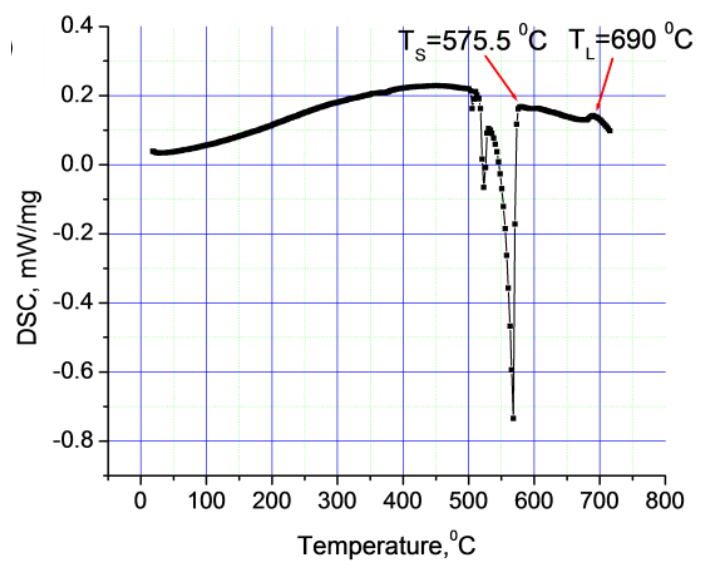

Fig.-1 DSC curve of hypereutectic al-18\% Si alloy containing $0.95 \% \mathrm{Fe}$.

\section{RESULTS AND DISCUSSION}

Fig. 2 shows the microstructure of $\mathrm{Al}-18 \% \mathrm{Si}$ alloy for as cast and semi-solid isothermal heated samples at $585{ }^{\circ} \mathrm{C}$ for range of 10 to $40 \mathrm{~min}$. The microstructure of as cast sample(see Fig.2 and Table 2) is characterized by needlelike iron-rich intermetallics phses, otherwise, plate-like and fine plate-like iron-rich intermetallics phases was observed for all samples heat treated in semi-solid state at $585{ }^{0} \mathrm{C}$ for range of 10-30 heating time. Pervious study [5] reported that the microstructure of semi-solid isothermal heat treated Al$18 \% \mathrm{Si}$ alloy is characterized by a relatively fine primary $\mathrm{Si}$ particles in a matrix of $\square-\mathrm{Al}$, eutectic $\mathrm{Si}$ and some intermetallic particles compared with as-cast one, moreover, At the early stages of heating time (up to $25 \mathrm{~min}$ ), A significant refinement of primary $\mathrm{Si}$ particle is observed in $\mathrm{Al}-18 \% \mathrm{Si}$ alloy when semi-solid isothermal heat treatment was applied at $585^{\circ} \mathrm{C}$ heating temperature.

Table-2 Quantitative measurement of structural features of as cast $\mathrm{Al}-18 \% \mathrm{Si}$ alloy.

\begin{tabular}{|l|l|}
\hline$\alpha$-Al grain size, $\mu \mathrm{m}$ & 155 \\
\hline$\alpha$-Al grain sphericity & 0.35 \\
\hline Primary Si particle size, $\mu \mathrm{m}$ & 70 \\
\hline Primary Si particle sphericity & 0.50 \\
\hline Hardness, HRB & 62 \\
\hline
\end{tabular}
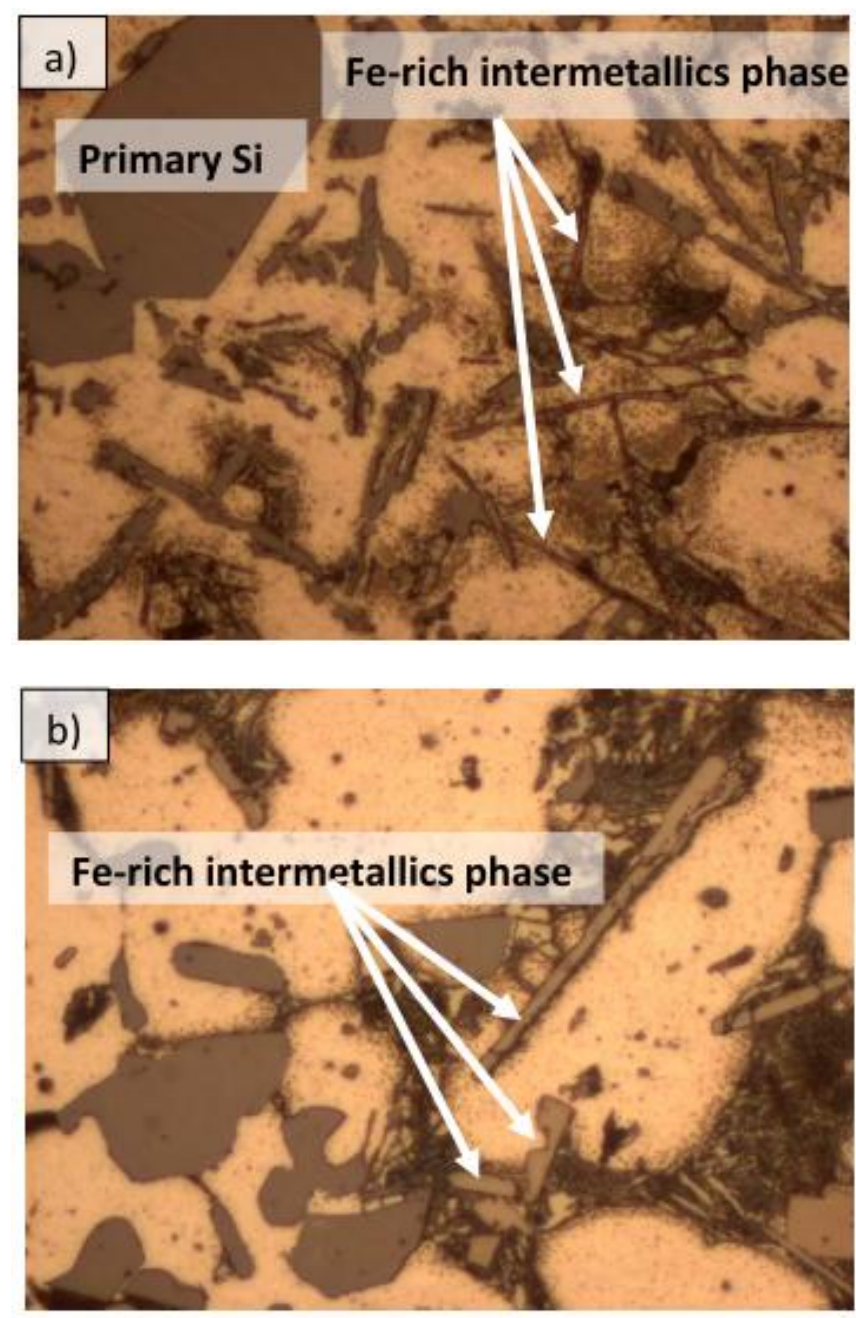

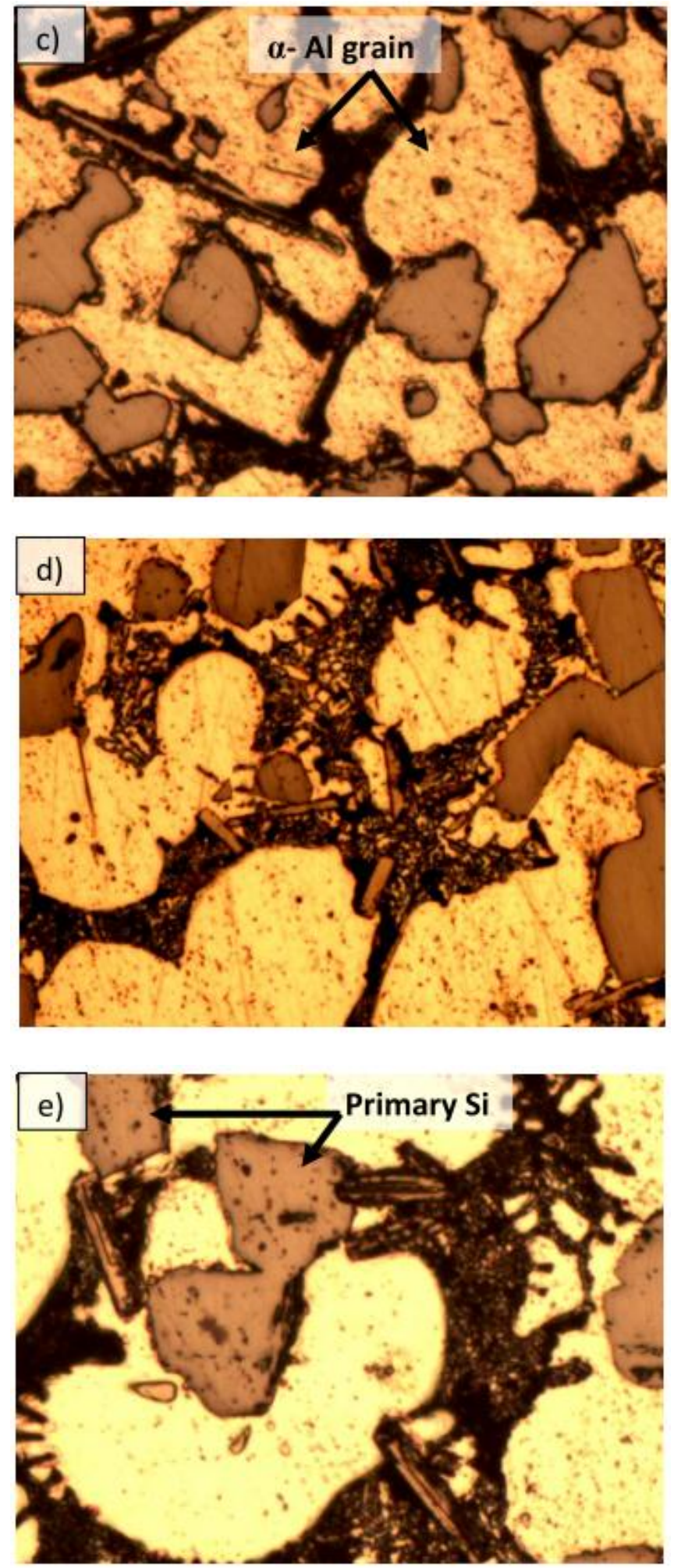

Fig.-2 Microstructure of Al- 18\% Si alloy for as cast and isothermal heat treated at $585{ }^{\circ} \mathrm{C}$; a) As cast b) heating time of $10 \mathrm{~min}$; c ) heating time of $20 \mathrm{~min}$; d ) heating time of 30 min; e ) heating time of $40 \mathrm{~min}$.

Fig.3 shows generally that hardness values for semi-solid heat treated Al-18\% Si Alloy for all heating time range (10$40 \mathrm{~min}$ ) are relatively higher compared with the as cast one. Hardness value of $72.5 \mathrm{HRB}$ is achieved by heating $\mathrm{Al}-18 \%$ $\mathrm{Si}$ alloy at heating temperature of $585{ }^{0} \mathrm{C}$ for $25 \mathrm{~min}$.
Hardness value increases with heating time up to $20 \mathrm{~min}$ due to the grain refining of primary $\mathrm{Si}$ particle and $\alpha-\mathrm{Al}$ grain, meanwhile, hardness value decreases with heating time above $25 \mathrm{~min}$ due to coalescence and particles agglomerations.

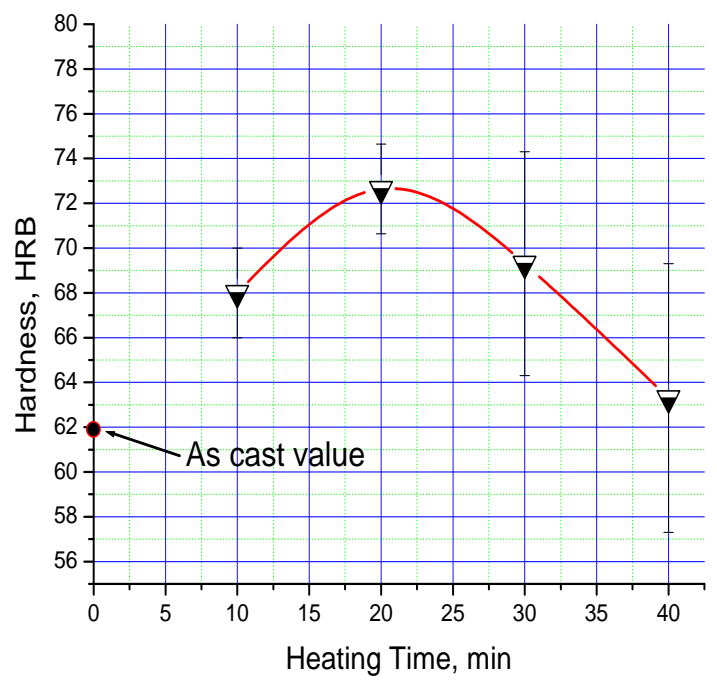

Fig.-3 Hardness of as cast and isothermal heat treated Al$18 \% \mathrm{Si}$ alloy at $585^{\circ} \mathrm{C}$ as a function of heating time.

The variation in weight loss of $\mathrm{Al}-18 \%$ Si alloy containing $0.95 \% \mathrm{Fe}$ measured as a function of semi-solid heating at $585^{\circ} \mathrm{C}$ for 10 to $40 \mathrm{~min}$ heating time is presented in Fig.4. It is clear that at early stage of heating time (up to about 25 min.) the weight loss significantly decreases (wear resist increases) by increasing the heating time. Increasing the heating time above $25 \mathrm{~min}$. shows increasing in weight loss (wear resist decreases).

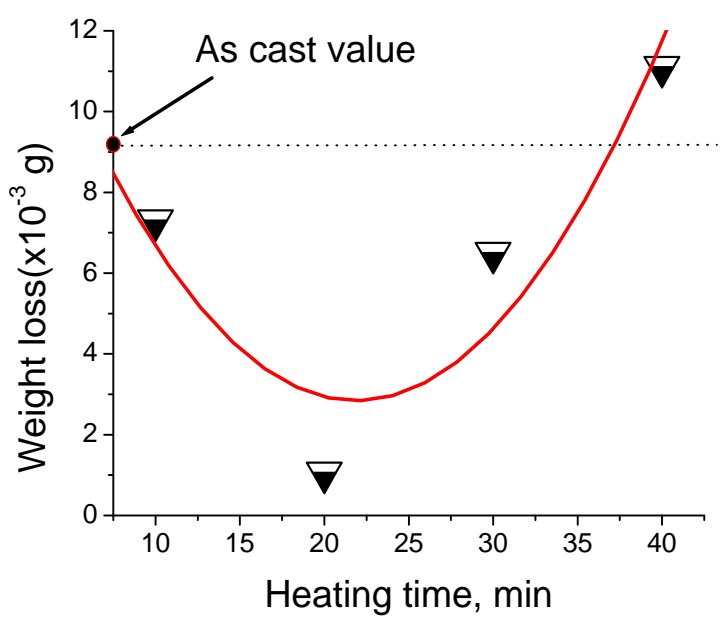

Fig. - 4 Weight loss as a function of heating time.

Pervious study [6] indicate that The isothermal holding at the temperature near the eutectic point enhances the separation of $\alpha(\mathrm{Al})$ and $\mathrm{Si}$ eutectic phases, and therefore, the $\mathrm{Al}$ in the solution can easily precipitate on the existing $\alpha$ (Al). After the fine holding time, low melting point phase melts which distributes in the recrystallization grain 
boundaries or within grain as a result of the holding temperature that is higher than the solidus. With increasing holding time, many small liquid droplets within grain combine and form several big liquid drops in order to reduce the interfacial energy. After full recrystallization and then increasing the holding time, Ostwald ripening and coalescence play an important role to make the average size of the solid particles increase. Ostwald ripening involves the growth of large particles at the expense of small particles, and it is governed by the Gibbs-Thompson effect which alters the chemical potential of solutes at the particle/liquid interface, depending on the curvature of the interface [7].

The reduction of interfacial energy between the solid phase and liquid phase provides the driving force for grain coarsening. Note that there are still a small number of irregular-shaped grains, which probably result from the coalescence of two spheroidal grains. Moreover, these irregular-shaped grains possibly originating from the extruded grains have not yet been completely broken up. When the holding time is long enough, which makes the solid volume fraction lower down, the Ostwald ripening mechanism also begins after the structural coarsening. The larger grain gradually becomes spheroidal to lower the solid/liquid interfacial energy. It is clear that the high semisolid It is clear that the high semisolid isothermal temperature reduces the volume fraction of solid and accelerates the spherical evolution of the solid particles, long isothermal time makes the semisolid particles more globular, but the size of the particles would grow larger [6].

It is clear that by increasing the heating time at semi-solid temperature the amount of liquid will increases. The separation of $\alpha$-Al phase leads to segregation of iron-rich intermetallic phase to the liquid grain boundary that change its morphology make it fineer and wider( plate-like), as shown in Fig.2. Increasing of hardness by heating time up to 25 min (see Fig. 3) could be due to improve matrix structure and primary $\mathrm{Si}$ as well as the iron-rich intermetallic phase morphology. However, semi-solid isothermal heat treatment performed above heating time of $25 \mathrm{~min}$ might result in coarsening and agglomeration of primary $\mathrm{Si}$.

Current and previous study [1] in a good agreement that the reduction in wear resistance of as-cast alloy compared to the semi-solid heat treated one, as shown in Fig. 4, can be explained based on the microstructural features of the alloys. Fig. 2 shows that addition semi-solid heat treatment of Al$18 \% \mathrm{Si}$ alloy containing Fe led to change of the precipitation $\beta$-phase intermetallic in the matrix. $\beta$-Al5FeSi from needlelike(as- cast samples) to fine plate-like( heat treated samples).

\section{CONCLUSIONS}

The effect of the semi-solid heat treatment on microstructure hardness and wear resist of hyper-eutectic Al-18\% Si alloy iron-rich intermetallics phses was investigated, which led to the following conclusions:

1. In as cast samples, needle-like iron-rich intermetallics phases was observed, otherwise, plate-like and fine plate- like iron-rich intermetallics phases was observed for all samples heat treated in semi-solid state.

2.Hardness values for semi-solid heat treated $\mathrm{Al}-18 \% \mathrm{Si}$ Alloy for all heating time range (10-40 $\mathrm{min}$ ) are relatively higher compared with the as cast one. Hardness value of $72.5 \mathrm{HRB}$ is achieved by heating Al-18\% Si alloy at heating temperature of $585{ }^{\circ} \mathrm{C}$ for $20 \mathrm{~min}$.

3. At the early stages of heating time (up to $25 \mathrm{~min}$ ), a significant decreases of weight loss is observed in $\mathrm{Al}-18 \%$ $\mathrm{Si}$ alloy when semi-solid isothermal heat treatment was applied at $585^{\circ} \mathrm{C}$ heating temperature. However, semi-solid isothermal heat treatment performed above heating time of 25 min might result in increases of weight.

4. The optimum semi-solid heating treatment condition was achieved at the temperature of $565{ }^{\circ} \mathrm{C}$ for the range of 15 to 25 mins.

\section{REFERENCES}

[1]. V. Abouei, S.G. Shabestari, H. Saghafian, Dry sliding wear behaviour of hypereutectic $\mathrm{Al}-\mathrm{Si}$ piston alloys containing iron-rich intermetallics, Materials Characterization, 61, 11, 2010, 1089-1096.

[2]. Lasa L, Rodriguez-Ibab JM. Mater Sci Eng A, 2003, pp 363-193.

[3]. A.Hekmat-Ardakan, F. Ajersch, "Thermodynamic evaluation of hypereutectic Al-Si (A390) alloy with addition of Mg, Acta Materialia," Vol.58 ,2010, pp 34223428 .

[4]. Taghiabadi R, Ghasemi HM, Shabestari SG. Effect of iron-rich intermetallics on the sliding wear behavior of $\mathrm{Al}-$ Si alloys. Mater Sci Eng A 2008;490:162-70.

[5]. N. Fathy, Microstructural Evolution of Hyper-Eutectic Al-18\% Si Alloy during Semi-Solid Isothermal Heat Treatment International Conference on Research in Science, Engineering and Technology (ICRSET'2013) Nov. 13-14, 2013 Kuala Lumpur (Malaysia)

[6]. M. TEBIB, J. B. MORIN, F. AJERSCH, X. GRANT CHEN,2010 "Semi-solid processing of hypereutectic A390 alloys using novel rheoforming process, " Trans. Nonferrous Met. Soc, China Vol.20 PP 1743-1748.

[7]. ZHAO Zu-de, CHEN Qiang, WANG Yan-bin, SHU Da-yu, 2009 "Microstructural evolution of an ECAE-formed ZK60-RE magnesium alloy in the semi-solid state" Journal of Materials Science and Engineering A,Vol. 506, PP 8-15. 